\title{
A Monte Carlo Approach to Estimate the Stability of Soil-Rock Slopes Considering the Non-Uniformity of Materials
}

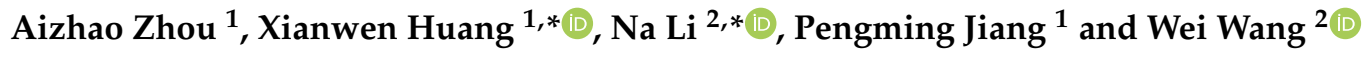 \\ 1 Department of Civil and Architecture Engineering, Jiangsu University of Science and Technology, \\ Zhenjiang 212003, China; zhouaizhao@126.com (A.Z.); jkdkjcjpm@163.com (P.J.) \\ 2 School of Civil Engineering, Shaoxing University, Shaoxing, Zhejiang 312000, China; wellswang@usx.edu.cn \\ * Correspondence: huangxianwen194@163.com (X.H.); lina@usx.edu.cn (N.L.)
}

Received: 11 February 2020; Accepted: 2 April 2020; Published: 8 April 2020

\begin{abstract}
A soil-rock slope is a heterogeneous slope composed of soil and rocks that is widely distributed throughout the world. In order to accurately analyze the slope stability of soil-rock mixture, based on a Monte Carlo algorithm (fuzzy-based method), a symmetrical stability analyzing method for soil-rock slopes is proposed, considering the dispersion of strength of soil-rock mixtures. In analyzing it, the numerical model is symmetrical to the real soil-rock slope in geometry and material properties. In addition, the effect of rock content to slope stability was studied by this symmetrical method. The specific work of this paper is as follows: (1) The acquisition method of random number series for the Monte Carlo algorithm and the method of slope stability analysis, using the Monte Carlo method, are introduced. (2) According to in situ samples and remade samples, the strength characteristics of soil-rock mixtures were measured with different rock contents, which proved the scatter of strength of soil-rock mixtures. (3) Based on the measured strength parameters of soil-rock mixtures and the slope landslide, the reliability in analyzing results and superiority in calculating time of using the Monte Carlo method to analyze stability of soil-rock slopes are detailed. (4) The stability of soil-rock slopes with different rock content is discussed with the Monte Carlo method, and it is concluded that with the increase of rock content, the stability of a soil-rock slope decreases first and then increases, and the minimum safety factor is acquired at $20 \%$ rock content. (5) Based on a large number of calculation examples, the applied situations of the Monte Carlo method to analyze stability of soil-rock slopes are detailed according to sampling results and rock size.
\end{abstract}

Keywords: soil-rock mixtures; slope stability; Monte Carlo method; soil-rock interface; rock content

\section{Introduction}

Soil-rock slopes, consisting of soil and rocks, are extremely heterogeneous slopes that are usually distributed in quaternary loose accumulation layers and mainly formed by residual weathering, landslides, flood alluvium, and so on [1-3]. The great difference between soil and rocks in strength and particle size leads to different mechanical properties in soil-rock mixtures [1,4-7]. In some areas, the mixtures of soil and rocks are usually recognized as bimrocks $[2,8]$. It is a common slope structure (a soil-rock slope is shown in Figure 1a) and engineering material (artificial materials are shown in Figure 1b), usually viewed in the Three Gorges region of China and the west of China [9-11]. Hence, when constructing a highway or railway on a natural or manually filled soil-rock slope, it is necessary to evaluate the stability of the soil-rock slope to ensure the safety of the project and prevent a landslide and failure of the slope. 


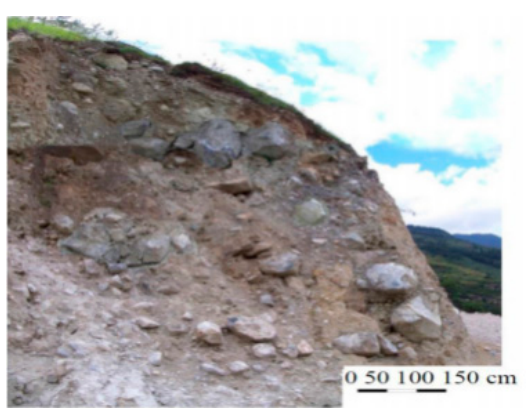

(a)

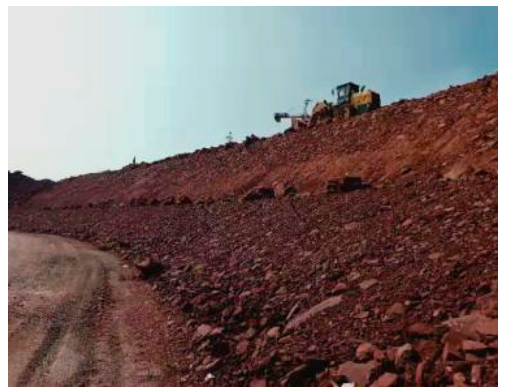

(b)

Figure 1. Examples of soil-rock slopes: (a) natural soil-rock slope [12]; (b) manually filled soil-rock slope.

In the past few decades, many scholars have studied the stability of soil-rock slopes, and lots of achievements have been obtained, such as failure models, etc. [13-15]. Liu et al. [3,16] combined random establishment method of rock contours and Finite Element Methods, studied the effect of regular rock distribution to the slope stability, and concluded that the stability of a soil-rock slope improves with the increase of rock contents, and the increasing amplitude is highly related to rock distribution characteristics in slopes. In addition, Liu et al. [17] adopted a two-phase medium that soil and rocks were considered to have different undrained shear strength to study the stability of a soil-rock slope by FEM and found that the slope obtains the maximum and minimum safety factor when the rocks' long axis is vertical and parallel to the slope surface, respectively, in which the minimum safety factor is always larger than the uniform soil slope. As well as these studies, many model tests and numerical analyses (FEM, LAM, and NMM) $[13,18]$ on soil-rock slope stability were conducted $[13,14,16,18]$, and one unified conclusion was obtained that the soil-rock slope had a higher safety factor than those with uniform soils, and the improved effects to slope stability increased with the increase of rock contents.

However, with the deepening study on soil-rock slope stability, more and more research results show that the conclusion (the distribution of rocks improves the stability of the soil-rock slope) is suitable under certain conditions or assumptions. Hao et al. [19] found that the mechanical properties of the soil-rock mixtures were greatly affected by water content. The specimen obtained the lower cohesive force and internal friction angle when the water content was low or high, respectively. Liu et al. [3], according to the dry-wet cracks in soil-rock mixtures, concluded that the weakest part was in the interface between soil and rocks. Based on the results of the soil-rock mixtures from in situ testing and the statistical results of the soil-rock mixtures, Kalender et al. [8] found that the strength of the soil-rock mixtures was scattered, distributed in a range rather than a specific value, and had some distribution law which was suitable for analyzing via the fuzzy-based symmetrical method $[10,17]$. Based on references that study soil-rock mixtures $[1,5,6,19,20]$, it can be concluded that (1) the strength of soil-rock mixtures is affected by environments, such as water content, etc.; (2) the weakest part in the soil-rock mixture is in the interface between soil and rocks; and (3) the strength testing result of the soil-rock mixtures is scatter, distributed in a range, and has some distribution law.

In addition to the great progress in soil-rock mixtures, there has been less progress in studies of soil-rock slopes. Huang et al. [21] studied the response characteristic of a soil-rock slope under seismic load by FEM and concluded that the maximum horizontal acceleration of the soil-rock slope surface was greater than those slopes without rocks, in other words, the slope was more prone to landslides than a uniform soil slope; Zhou et al. [22] measured the response characteristic of a soil-rock slope under artificial rainfall and found that the soil-rock slope was more easily affected by rainfall, which was similar to Hao's conclusions. According to the stability of soil-rock slopes in the Three Gorges area under the condition of rainfall and water level changes, Xiong et al. [23] points out that the soil-rock slope is more prone to instability under continuous rainfall and low water level. Based on the above analysis, it can be found that the stability of the soil-rock slope is lower than the uniform soil slope 
under certain conditions, which are mainly related to the environment (rainfall, water, etc.) and the type of load.

Based on the research achievements in the field of soil-rock mixtures and soil-rock slopes, it should be observed that, when estimating the stability of soil-rock slopes, researchers should not only consider the improved effects of rocks to slope stability but also (1) the weaker soil-rock surface; (2) the scatter strength characteristic of soil-rock mixtures; and (3) the environment (rainfall, water, etc.) and the type of load.

To better estimate the stability of soil-rock slopes, according to the original slope characteristic in geometry and material properties, symmetrical numerical analyzing models were established. In material parameters, according to the measured strength of soil-rock mixtures, a Monte Carlo method that was a fuzzy-based symmetrical method was put forward. The specific analysis process with the Monte Carlo method was as follows: first, the in situ samples and the remade samples were obtained from in situ drilling and sampling from landslides, respectively. Second, triaxial tests were used to measure the strength of soil-rock mixtures that were used in numerical models, to achieve symmetry in material strength between numerical model and real slope. Third, based on the measured strength parameters, the stability of the soil-rock slope was studied by the Monte Carlo method, and the statistical value of safety factor of the soil-rock slope was obtained. Then, to discuss the reliability of the Monte Carlo method, the analyzed results were compared with those obtained by Liu's method [3]. Finally, based on a large number of calculation examples, the applied situations of the Monte Carlo method to analyze stability of the soil-rock slope were detailed according to sampling results and rock size.

\section{The Monte Carlo Method for Soil-Rock Slopes}

The Monte Carlo algorithm is a statistical calculation method that can effectively analyze the influence of uncertain factors on calculation results. Its rationality has been verified in the $\pi$ evaluation [24], reliability prediction of machinery [25], and slope stability analysis [26]. For considering the uncertain factors related to the slope stability, during the analysis, the strength parameters (cohesion and friction angle) of the soil-rock mixtures were set to random variables, and then the stability and failure characteristics of the slope were analyzed by a large number of repeated calculations. The analysis results show good reliability in analyzing stability of uniform soil slopes with the Monte Carlo algorithm [26-28]. However, the above analysis focuses on the uniform soil slope, without considering the weakening effect of soil-rock interface on the slope stability and the strengthening effect of rock distribution on the slope stability. Therefore, in order to consider the influence of the soil-rock mixtures' scatter strength and the rock distribution uncertainty on the slope stability at the same time, a Monte Carlo algorithm suitable for the stability analysis of soil-rock slopes was proposed. In the future, it expected to use this method to study the soil-rock slope stability reinforced by cement $[29,30]$, new composite materials [31,32], anchors and geo-grids, etc.

When analyzing the stability of soil-rock slopes, it should be observed that the rock size in soil-rock slope is limited in $0.1 \sim 0.4 \mathrm{Ls}$ (Ls is the width of slope) $[3,16,18]$. When the rock size is smaller than 0.1 Ls, rock distribution has less of an effect on slope stability, and the slope can be treated as soil slope. When the rock size is greater than $0.4 \mathrm{Ls}$, the rock distribution has a decisive influence on slope stability and failure modes, and the slope stability can be analyzed as soil slope, considering large rocks distribution.

\subsection{Generation of Independent Random Variables}

Based on the strength distribution parameters of the soil-rock mixture obtained from in situ samples and remade samples, two sets of independent random variables were constructed, and the specific generation method was as follows.

Step 1, determining the probability density function of the sample: examining whether the cohesion and internal friction angle sample data in the analytical model are subject to a normal 
distribution. If it fits the normal distribution, the probability density function is Equation (1); otherwise, it is considered according to corresponding distribution characteristic [33].

$$
f(x)=\frac{1}{\sigma \sqrt{2 \pi}} \exp \left[\frac{-(x-\mu)^{2}}{2 \sigma^{2}}\right], x>0
$$

where $\mu$ is the mean value, and $\sigma$ is the standard deviation.

Step 2, generation of random numbers: two sets of uniformly distributed random numbers were generated by using random algorithm (Random). Then, the multiplicative congruence method was used to generate an integer uniformly distributed random number sequence, and the calculated function is as follows:

$$
I_{n+1}=\bmod \left[\left(a I_{n}+b\right) / m\right]
$$

where $I_{n}$ is a random number sequence; $a$ and $b$ are random integers; and mod is the remainder calculation, which is also the source of the randomness of the algorithm. The finally obtained two groups of uniformly distributed random sequences, $A_{n}$ and $a_{n}$ (in the range of 0 to 1 ), are as follows, respectively:

$$
\begin{gathered}
A_{n}=\frac{I_{n}}{\text { float }(m)} \rightarrow[0,1] \\
a_{n}=\frac{I_{n}}{\text { float }(m-1)} \rightarrow[0,1]
\end{gathered}
$$

where "float" represents converting $m$ from an integer type to a floating-point type.

Step 3, constructing a normal distribution variable: Using the obtained two sets of uniformly distributed random numbers, two sets of variables conforming to the normal distribution were constructed by the Box-Muller method [34,35].

Assuming that the joint probability density distribution function of $x_{1}, x_{2}$ is $p\left(x_{1}, x_{2}\right)$ and $y_{1}, y_{2}$ are functions of $x_{1}, x_{2}$, then the joint probability density distribution function of $y_{1}, y_{2}$ is as follows:

$$
p\left(y_{1}, y_{2}\right)=p\left(x_{1}, x_{2}\right)\left|\frac{\partial\left(x_{1}, x_{2}\right)}{\partial\left(y_{1}, y_{2}\right)}\right|
$$

where $\left|\frac{\partial\left(x_{1}, x_{2}\right)}{\partial\left(y_{1}, y_{2}\right)}\right|$ is the Jacobian matrix of $x$ to $y$.

Because $x_{1}$ and $x_{2}$ are mutually independent uniformly distributed random variables in the $[0,1]$ interval, we obtain the following equation:

$$
p\left(x_{1}, x_{2}\right)=p\left(x_{1}\right) p\left(x_{2}\right)=1
$$

Then,

$$
p\left(y_{1}, y_{2}\right)=\left|\frac{\partial\left(x_{1}, x_{2}\right)}{\partial\left(y_{1}, y_{2}\right)}\right|
$$

Assuming

$$
\begin{aligned}
& y_{1}=\sqrt{-2 \operatorname{In} x_{1}} \cos \left(2 \pi x_{2}\right) \\
& y_{2}=\sqrt{-2 \operatorname{In} x_{1}} \sin \left(2 \pi x_{2}\right)
\end{aligned}
$$

it can be obtained that

$$
\begin{aligned}
& x_{1}=\exp \left[-0.5\left(y_{1}^{2}+y_{2}^{2}\right)\right] \\
& x_{2}=\frac{1}{2 \pi} \arctan \frac{y_{2}}{y_{1}}
\end{aligned}
$$

This can be solved as follows: 


$$
\begin{aligned}
& p\left(y_{1}, y_{2}\right)=\left|\frac{\partial\left(x_{1}, x_{2}\right)}{\partial\left(y_{1}, y_{2}\right)}\right|=p\left(y_{1}\right) p\left(y_{2}\right) \\
& =-\left[\frac{1}{\sqrt{2 \pi}} \exp \left(-\frac{y_{1}^{2}}{2}\right)\right]\left[\frac{1}{\sqrt{2 \pi}} \exp \left(-\frac{y_{2}^{2}}{2}\right)\right]
\end{aligned}
$$

Equation (10) can prove that $y_{1}, y_{2}$ are random variables that are independent of each other and follow a normal distribution. Therefore, two sets of independent random numbers conforming to the normal distribution can be obtained based on Equation (8).

\subsection{Stability Analysis of the Soil-Rock Slope by the Monte Carlo Method}

\subsubsection{Stability Analysis Process for the Soil-Rock Slope}

The application of the Monte Carlo algorithm in the stability analysis of soil-rock mixture slope mainly included four steps, as shown in Figure 2, which are sample acquisition, model parameter input, cumulative calculation, and statistical results analysis. The specific description of each step is as follows.

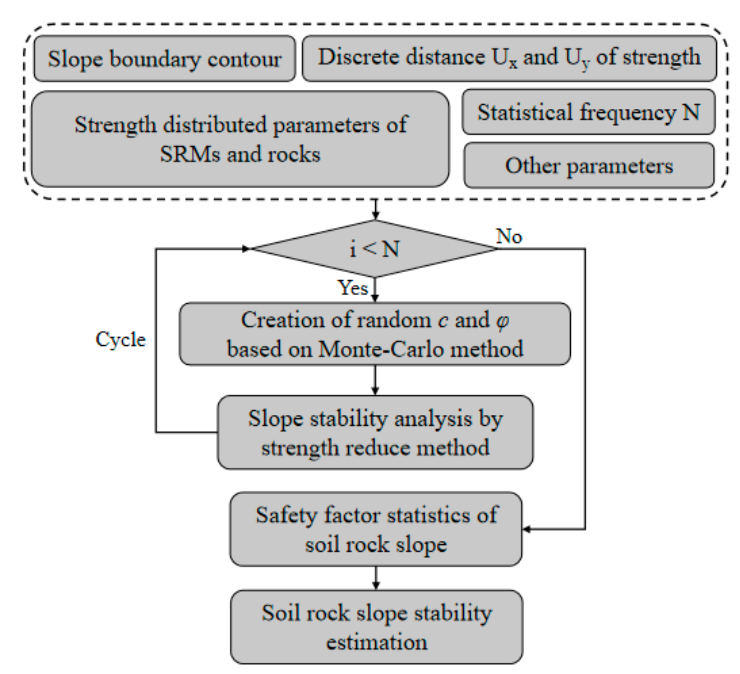

Figure 2. The stability analysis process of the soil-rock slope.

Sample acquisition: Based on the in situ samples results or remade sample results, three typical strength parameters of soil-rock mixtures were obtained, strength of soil-rock interface (direct shear test) $[1,36,37]$, soil-rock mixtures (triaxial test) and rocks (point pressure test), and the corresponding frequency-strength relationships with cumulative frequency of 1 , which are described in Figure 3.

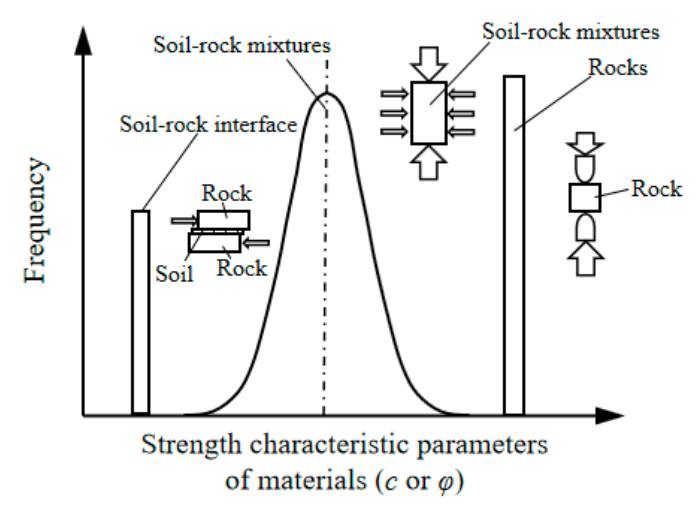

Figure 3. Variations of frequency and strength of soil-rock mixtures. 
Model parameter input: This step mainly involved the input of some geometric parameters and strength parameters of the material in the model, for example, the boundary contour of the soil-rock slope, the material strength parameter in the sample acquisition step, the Monte Carlo repeat calculation number $\mathrm{N}$, and some other parameters, and fluctuation scale of the material strength in the horizontal direction (Ux) and the vertical direction (Uy). Among them, the size of Ux and Uy should be based on in situ drilling data or geological structure, which is especially valuable in layered soil analysis.

Cumulative calculation: According to input repeated calculations, N, calculations were conducted repeatedly, and the independent random variables were obtained with the method of Section 2.1.

Statistical results analysis: The maximum, minimum, mean, and standard deviation of the safety factor of the soil-rock slope were obtained by statistical calculation, using the strength reduction method of FEM.

\subsubsection{Analysis Model of the Soil-Rock Slope}

Based on treatment engineering of soil-rock slopes in Zhenjiang, Jiangsu Province, China, the corresponding soil-rock slope model was established. As shown in Figure 4, part of the soil-rock slope is subject to landslides under the action of heavy rainfall. Therefore, it is necessary to evaluate the stability of the remaining slope that has not experienced a landslide and determine whether it needs to be treated. A typical slope section with a height of $13 \mathrm{~m}$ and a $45^{\circ}$ angle is shown in Figure 5 .

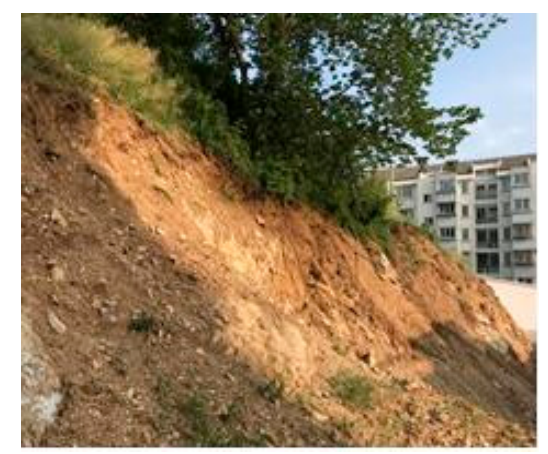

Figure 4. Failure scene of a soil-rock slope in Zhenjiang.

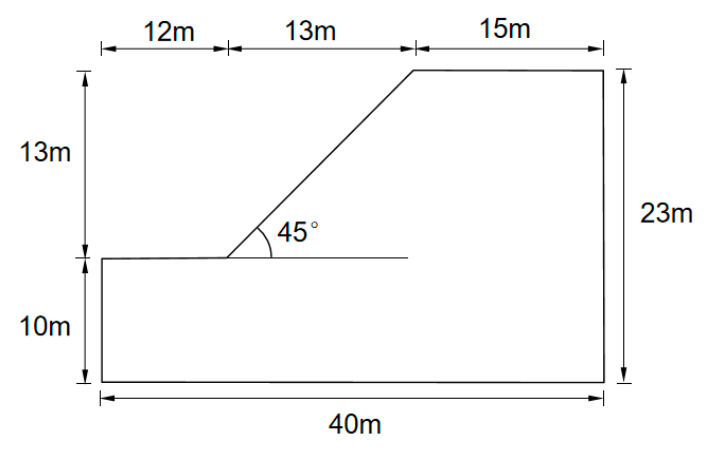

Figure 5. Geometric dimensions of the soil-rock slope model.

\section{Strength Measurement of Soil-Rock Mixtures}

\subsection{Acquisition of Samples}

In order to obtain the strength parameters of materials in soil-rock slopes, the sampling was carried out by means of drilling, as shown in Figure 6a. The sampling location was $30 \pm 5 \mathrm{~m}$ from the top of the slope. Due to the disturbance of the boring machine to the samples of soil-rock mixtures during the drilling process, the samples taken out were not complete, as shown in Figure $6 \mathrm{~b}$, and some samples were partially broken. When the in situ samples were taken from the ground, they were sealed and stored in a black plastic bag, and the water content was measured (14.6\%). 


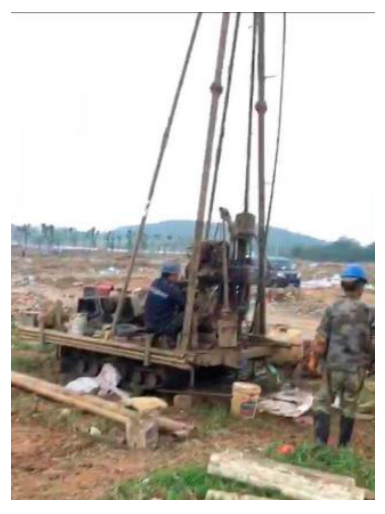

(a)

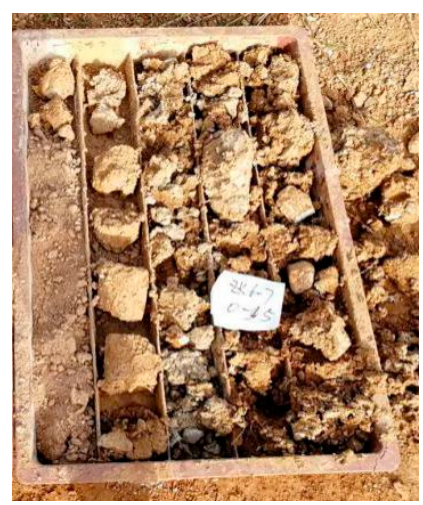

(b)

Figure 6. In situ sampling diagram: (a) in situ drilling pictures; and (b) samples from in situ drilling.

The samples obtained by in situ drilling were compacted by means of fixed compaction work (hit 35 times per layer by the sampler, divided into 5 layers of each sample), and the samples had a diameter of $70 \mathrm{~mm}$ and a height of $140 \mathrm{~mm}$. The prepared samples were measured for strength parameters (cohesion and internal friction angle) under consolidation and undrained conditions, using a TKA triaxial test apparatus, and the test confining pressures were set to 100, 200, and $300 \mathrm{kPa}$. The remade samples, using in situ drilling samples, were recognized as having in situ strength of soil-rock mixtures.

In order to carry out a more in-depth study of the mechanical properties of the soil-rock mixtures, a certain soil sample was taken from the landslides and sieved, to retain the rocks with a size range of 2 to $14 \mathrm{~mm}$. In soil-rock mixtures, due to the scale effect [1,11], it was very important to control suitable rock size, which played an important role on the triaxial testing results of soil-rock mixtures. According to References [38,39], the minimum rock size in soil-rock mixtures is advised to be the maximum value of $2 \mathrm{~mm}$ and $0.05 \mathrm{Lc}$ (Lc was the characteristic length of samples), and the maximum rock size is suggested to be $0.2 \mathrm{Lc}$. When the rock size is smaller than minimum size, the soil-rock mixtures can be recognized as uniform soil material that the rock distribution has less effect on the mixtures' strength. When the rock size is larger than maximum size, the rock distribution decides the mechanical properties of mixtures, and the mixtures should be called soil with larger rocks, rather than soil-rock mixtures. In the article, the minimum rock size of $3.5 \mathrm{~mm}(0.05 \times 70 \mathrm{~mm})$ was the best, but due to the limit of testing equipment, the rock size was finally set as $2 \mathrm{~mm}$, which could also obtain good testing results according to the pretesting results. The maximum rock size was set at $14 \mathrm{~mm}$ $(0.2 \times 70 \mathrm{~mm})$. After sample screening, the soil first underwent crushing and air-drying, and then was sealed and preserved after the water content was adjusted to $14.6 \pm 1 \%$. The remade samples using landslide samples were recognized as having the strength of remade soil-rock mixtures.

\subsection{Strength Measurement of Soil-Rock Mixtures}

\subsubsection{Testing Process}

The test of the soil-rock mixture consisted of four main parts: sample preparation, installation, consolidation, and test, which are described as follows.

Sample preparation: The soil and the rocks were uniformly weighed, and the samples were divided into 5 layers according to the "Geotechnical Test Standard" [39]. Each layer was compacted 35 times, and a screwdriver was used to scrape between the layers to ensure the uniformity of the sample.

Sample installation: The prepared sample was placed in a rubber film and mounted on a triaxial test device. Then, the confining pressure chamber was installed, and the confining pressure and back pressure devices were connected, and the confining pressure chamber was filled with water, as shown in Figure 7a. 


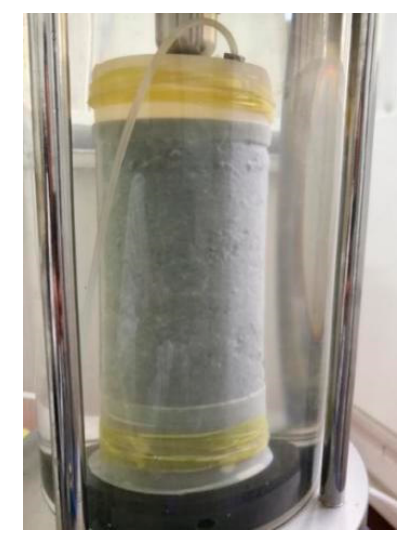

(a)

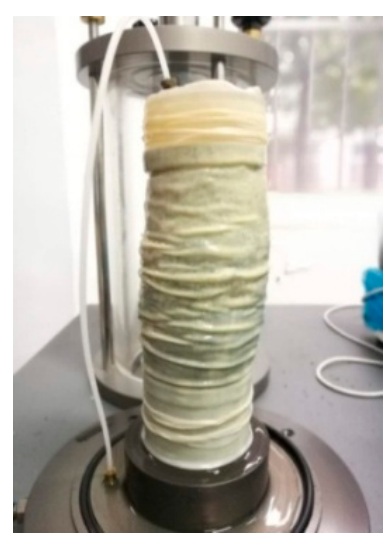

(b)

Figure 7. Sample test diagram: (a) sample before compression; and (b) sample after compression.

Sample consolidation: The confining pressure was set, the drainage valve was opened, and drainage consolidation was conducted.

Sample test: The drainage valve was closed, a triaxial test without drainage was conducted, and the stress-strain curve of soil-rock mixture was measured. In order to facilitate comparison, the strain measurement range was set as $0 \% \sim 20 \%$, where $20 \%$ was controlled by the strain of in situ samples at stress peak and effective testing strain range of equipment [5], and the maximum stress value during this period was the strength value of soil-rock mixture. The deformation result of the sample after measurement is shown in Figure $7 \mathrm{~b}$.

\subsubsection{Testing Scheme}

Physical parameters and grading curves of soil and rocks are shown in Table 1 and Figure 8, respectively. The specific sample test scheme is shown in Table 2, in which the content of soil-rock mixture is MBP (Mass Blocks Proportion, represents the Mass Proportion of Blocks to the mixtures that the definition of MBP references to Volumetric Block Proportions (VBP) [8]).

Table 1. Physical parameters of soil and rocks.

\begin{tabular}{|c|c|c|c|c|c|}
\hline Specimen & \multicolumn{5}{|c|}{ Physical Parameters } \\
\hline clay & $\begin{array}{l}\text { Specific Gravity } \\
2.75\end{array}$ & $\begin{array}{l}\text { Liquid Limit } \\
\quad 41.30 \%\end{array}$ & $\begin{array}{c}\text { Plastic Limit } \\
19.20 \%\end{array}$ & $\begin{array}{c}\text { Plasticity Index } \\
22.10 \%\end{array}$ & $\begin{array}{c}\text { Optimized Water Content } \\
\qquad 16 \%\end{array}$ \\
\hline rock & \multicolumn{2}{|c|}{$\begin{array}{l}\text { Point pressure strength } \\
1234 \mathrm{~N}\end{array}$} & \multicolumn{2}{|c|}{$\begin{array}{c}\text { crushing index } \\
23 \%\end{array}$} & $\begin{array}{l}\text { Density } \\
2.6 \mathrm{~g} / \mathrm{cm}^{3}\end{array}$ \\
\hline
\end{tabular}

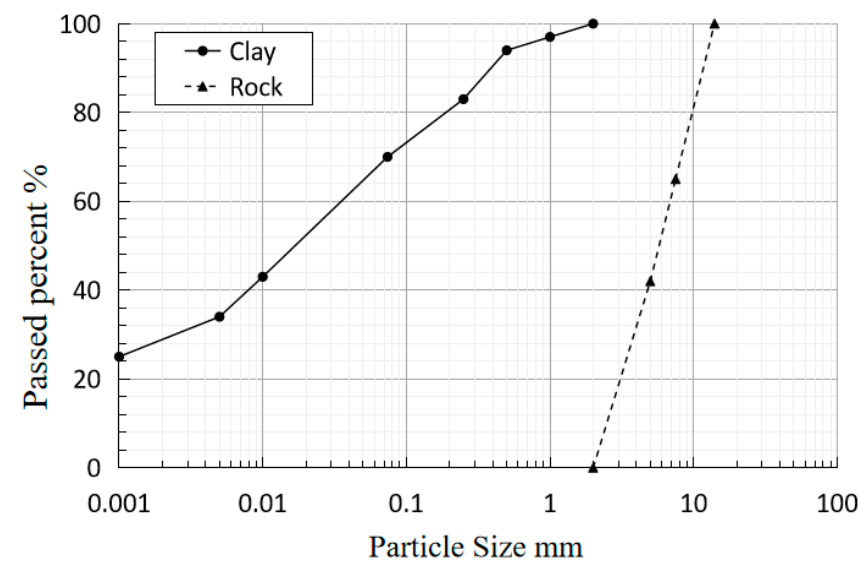

Figure 8. Curves of soil and rocks. 
Table 2. Testing scheme of soil-rock mixtures.

\begin{tabular}{|c|c|c|c|}
\hline \multicolumn{2}{|c|}{ In Situ Samples } & \multicolumn{2}{|c|}{ Remade Samples } \\
\hline Number & $\begin{array}{c}\text { Rock } \\
\text { Content }\end{array}$ & Number & $\begin{array}{c}\text { Rock } \\
\text { Content }\end{array}$ \\
\hline $\mathrm{I}-1$ & 18.4 & $\mathrm{R}-0-1 / 2 / 3 / 4 / 5$ & $0 \%$ \\
\hline $\mathrm{I}-2$ & 18.7 & $\mathrm{R}-1-1 / 2 / 3 / 4 / 5$ & $10 \%$ \\
\hline $\mathrm{I}-3$ & 20.3 & $\mathrm{R}-2-1 / 2 / 3 / 4 / 5$ & $20 \%$ \\
\hline $\mathrm{I}-4$ & 25.2 & $\mathrm{R}-3-1 / 2 / 3 / 4 / 5$ & $30 \%$ \\
\hline $\mathrm{I}-5$ & 25.9 & $\mathrm{R}-4-1 / 2 / 3 / 4 / 5$ & $40 \%$ \\
\hline $\mathrm{I}-6$ & 32.9 & $\mathrm{R}-5-1 / 2 / 3 / 4 / 5$ & $50 \%$ \\
\hline $\mathrm{I}-7$ & 33.7 & R-6-1/2/3/4/5 & $60 \%$ \\
\hline
\end{tabular}

\subsection{Testing Results}

According to the test scheme described in Section 3.2.2, the strength of the soil-rock mixture sample was tested, and the test results are shown in Figures 9 and 10.

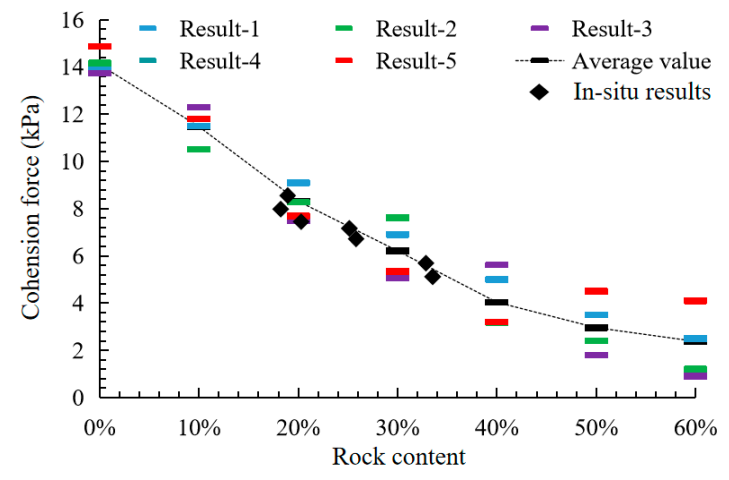

(a)

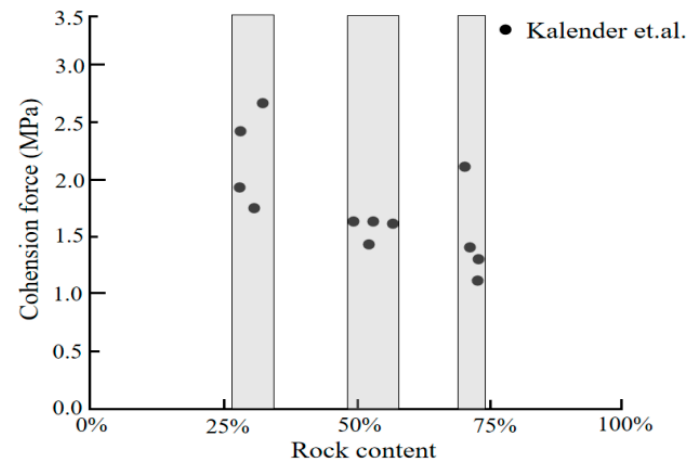

(b)

Figure 9. Cohesion results of soil-rock mixtures: (a) cohesion testing results of soil-rock mixtures; (b) cohesion results of Kalender et al. [8].

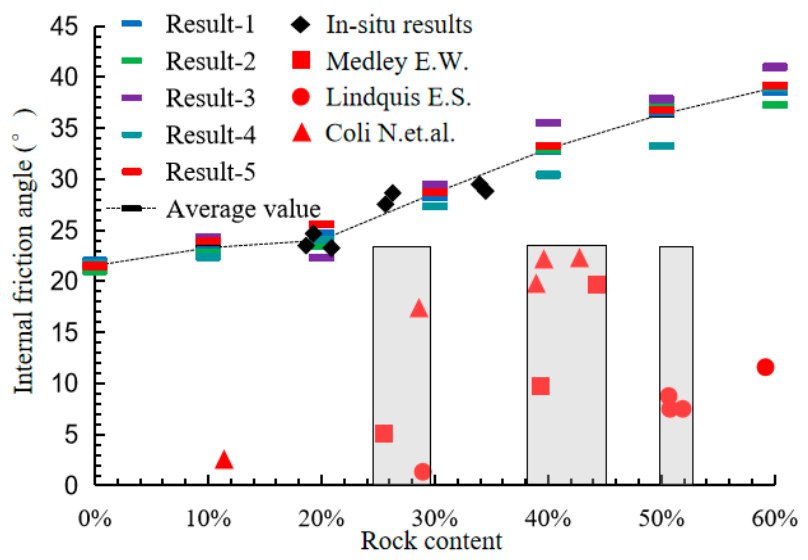

Figure 10. Internal friction angles' results of soil-rock mixtures.

According to the average cohesion of soil-rock mixtures shown in Figure 9a, it can be found that, with the increase of rock content, the average cohesion decreases, and the tendency is similar to the results of Kalender et al. [8]. Cohesion reflects the mutual attraction between substances, and its value is affected by the type of particles, particle size, and the filling medium (water, etc.). In soil-rock mixtures, with the increase of rock content, in the unit volume, more and more space was occupied by rocks, and the larger size of the rocks (greater than $2 \mathrm{~mm}$ ) and the different material structure from the 
soil are not conducive to the formation of cohesive force, so the cohesive force in the soil-rock mixture gradually decreased with the increase of rock content $[7,40,41]$.

Comparing the cohesion of soil-rock mixture with the same rock content in triaxial tests, it can be found that, with the same material and test conditions, the cohesion parameters of soil-rock mixture are not exactly the same but distributed in a certain range, and the scatter range of results increases with the increase of rock content. The reasons are as follows: the size, shape, distribution, and sampling error of the mixtures make it difficult to prepare the same mixture sample. Therefore, the cohesion of the mixture in the remade sample is scattered, meaning it is distributed in a range. The scattering of this cohesive force distribution also appears in the in situ samples. According to the test results of in situ drilling, the cohesive force of soil-rock mixture is also distributed scatteredly, when the content of rock is similar, and this can be explained by the heterogeneity of geological formations [8]. Therefore, combining Xu's studies $[2,8,11]$, in the premise of suitable rock size, it can be speculated that, in nature, the strength of soil-rock mixture is also distributed scatteredly. Hence, in order to evaluate the stability of soil-rock slopes more accurately, the cohesive force of soil-rock mixture should be a range rather than a fixed value.

Figure 10 reflects the test result of internal friction angle of soil-rock mixtures. It can be seen from the figure that the internal friction angle of soil-rock mixture gradually increases with the increase of rock content, and the increasing tendency is similar to Kalender et al. [8]. Internal friction angle is an important parameter of strength of soil-rock mixture, and its value is determined by the friction characteristics of particle surface, the inter-lock effects between particles, and the strength of particles [2,12,42]. With the increase of rock content, the number and volume of the rocks in the unit volume gradually increase, and the higher strength and inter-lock effect [5] of the rocks gradually play, showing a larger internal friction angle. The strengthening effect of internal friction angle should be considered when analyzing the stability of the soil-rock mixture slope.

Comparing the test results of internal friction angle of soil-rock mixture with the same rock content, it can be found that the internal friction angle parameters of soil-rock mixture are not exactly the same under the same material and test conditions, but are distributed in a certain range. The dispersion of this internal friction angle distribution also appears in the in situ samples and soil-rock mixtures in nature. The corresponding reason is related to the size, shape, distribution, and sampling error of soil-rock mixtures. Hence, in order to evaluate the stability of soil-rock slopes more accurately, the internal friction angle of soil-rock mixture should be a range rather than a fixed value.

\section{Comparison with Liu's Method}

In 2018, Liu et al. [3] studied the stability of soil-rock slopes and proposed a calculation method for the stability of soil-rock slopes, considering the distribution characteristics of rocks. In Liu's method, they established soil-rock slope models, considering rock size and shapes, and then the strength parameters of soil-rock mixtures were divided into soil and rocks, respectively, and ignored the strength scatter characteristic of soil-rock mixtures and interaction between soil and rock. To better estimate the stability of the soil-rock slope in Zhenjing, the Monte Carlo method (this article) and Liu's method were all used, and the corresponding calculating parameters and results are shown in Tables 3 and 4, respectively. Table 3 details the rock content (which is Volumetric Block Proportion, and VBP $=0.9 \mathrm{MBP}$ ) of the randomly generated soil-rock slope, the calculation time, and the safety factor, in which the size range of the rock is set between 1 and $3 \mathrm{~m}$. Figure 11 shows the development path of the plastic belt (sliding belt) $[3,16,27]$ of the soil-rock slope under six specific examples.

Table 3. Calculation model parameters of Liu's method.

\begin{tabular}{cccccccc}
\hline Number & VBP & Time (s) & Safety Factor & Number & VBP & Time (s) & Safety Factor \\
\hline C-1 & $22.50 \%$ & 163 & 1.172 & C- 4 & $22.40 \%$ & 140 & 1.238 \\
C-2 & $22.00 \%$ & 135 & 1.25 & C-5 & $23.10 \%$ & 149 & 1.266 \\
C-3 & $22.50 \%$ & 128 & 1.164 & C-6 & $22.80 \%$ & 146 & 1.227 \\
\hline
\end{tabular}


Table 4. Calculation model parameters of the Monte Carlo method.

\begin{tabular}{|c|c|c|c|c|c|c|c|c|}
\hline Number & $\begin{array}{l}\text { Cohesion } \\
\text { (kPa) }\end{array}$ & $\begin{array}{l}\text { Internal } \\
\text { Friction } \\
\text { Angle }\left({ }^{\circ}\right)\end{array}$ & $\begin{array}{c}\text { Standard } \\
\text { Deviation of } \\
\text { Cohesion (kPa) }\end{array}$ & $\begin{array}{c}\text { Standard Deviation } \\
\text { of Internal Friction } \\
\text { Angle }\left({ }^{\circ}\right)\end{array}$ & Time (s) & $\begin{array}{l}\text { Repeated } \\
\text { Times }\end{array}$ & $\begin{array}{l}\text { Safety } \\
\text { Factor }\end{array}$ & $\begin{array}{c}\text { Standard } \\
\text { Deviation of } \\
\text { Safety Factor }\end{array}$ \\
\hline D-0 & 7.3 & 26.4 & 0 & 0 & $47 \mathrm{~s}$ & 1 & 0.929 & 0 \\
\hline D-1 & 7.3 & 26.4 & 0.9 & 1.05 & 953 & 50 & 0.937 & 0.00959 \\
\hline D-2 & 7.3 & 26.4 & 0.9 & 1.05 & 965 & 50 & 0.965 & 0.01131 \\
\hline
\end{tabular}

Details: Mass Block Proportion $(\mathrm{MBP})=25 \%, \mathrm{Ux}=\mathrm{Uy}=0.5 \mathrm{~m}$.

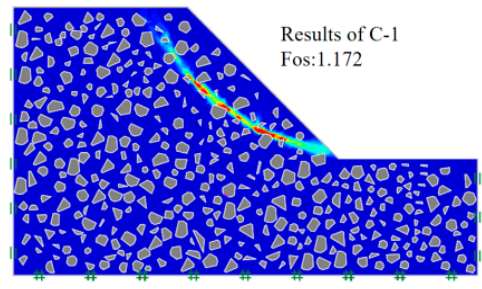

(a)

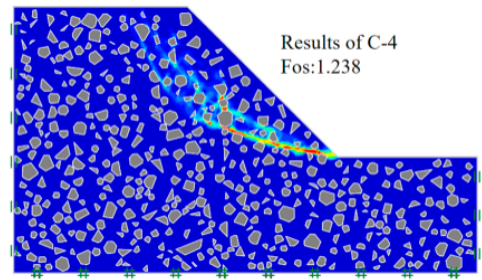

(d)

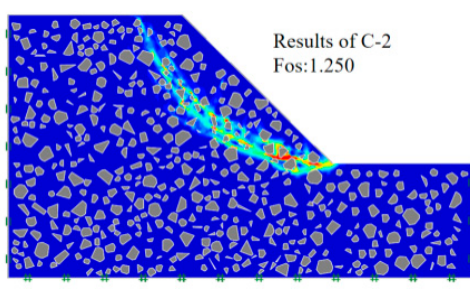

(b)

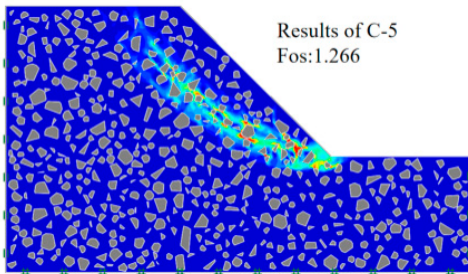

(e)

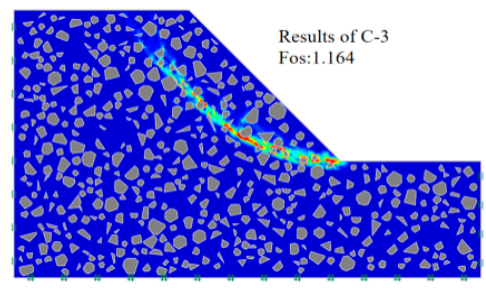

(c)

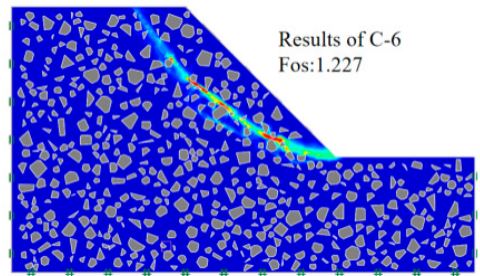

(f)

Figure 11. The stability analysis results of the soil-rock slope with Liu's method: (a) calculation results of C-1; (b) calculation results of C-2; (c) calculation results of C-3; (d) calculation results of C-4; (e) calculation results of C-5; and (f) calculation results of C-6.

It can be seen from Table 3 that, in Liu's calculation method, the average calculation time of a single model is $143.5 \mathrm{~s}$, and $80 \%$ of the time is spent on generating the soil-rock slope model. The average safety factor of the slope is 1.2195 , the minimum value is 1.164 , and the maximum value is 1.266. It can be seen from the calculation results that, according to Liu's calculation method, the slope should be stable, which means there should be no landslide, which is contradictory to the real slope that had experienced a landslide.

The stability of the soil-rock slope was studied by the Monte Carlo method and the specific model parameters, and calculation results are shown in Table 4 and Figure 12.

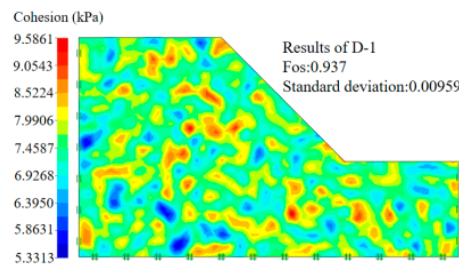

(a)

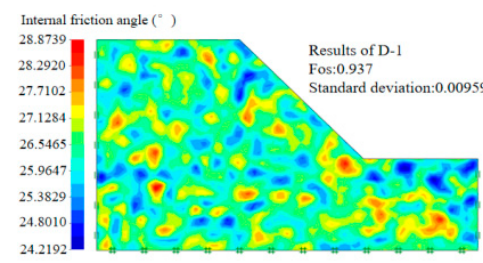

(b)

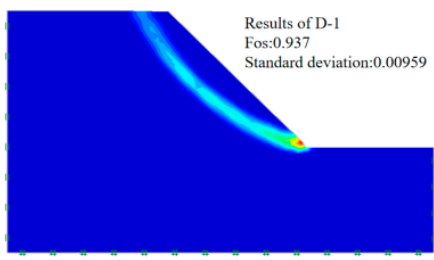

(c)

Figure 12. Results of soil-rock slope analysis of the D-1 group obtained by the Monte Carlo method: (a) cohesion distribution picture; (b) internal friction angle distribution picture; and (c) slope plastic belt picture.

As shown in Table 4, three sets of calculation models, namely D-0, D-1, and D-2, were set respectively. The D-0 group did not consider the dispersion of cohesion and internal friction angle. The calculation 
time was $47 \mathrm{~s}$, and the safety factor was 0.929 . In D-1 group, the strength parameters of soil-rock mixtures were considered to be scattered according to testing results and ignored the strengthening effect of the rock strength on the slope. The calculation time was $953 \mathrm{~s}$, the number of repetitions was 50, and the obtained slope safety factor was 0.937 . In the D-2 group, the strength parameters of soil-rock mixtures were considered to be scattered, and some mixtures' strength were changed to rock's strength $(c=1000 \mathrm{k}$ Pa and $\varphi=40^{\circ}$ ) for considering the effect of rock to slope. The calculation time was $965 \mathrm{~s}$, the number of repetitions was 50, and the obtained slope safety factor was 0.965 .

Figure 12 shows an example in the random calculation process of the D-1 group of soil-rock mixture slope. It can be seen from Figure 12a that the cohesion of materials in the soil-rock slope is non-uniform and distributed randomly within the range of 5.33 9.59. It can be seen from Figure $12 \mathrm{~b}$ that the internal friction angle of materials in the soil-rock slope is non-uniform and distributed randomly within the range of 24.21 28.87. Figure 12c shows the plastic belt of the soil-rock slope in this case.

Figure 13 shows an example in the random calculation process of the D-2 group of soil-rock mixture slope. It can be seen from Figure 13a that the materials in the soil-rock slope are not uniformly distributed (3.98 1000 kPa), and this is mainly reflected in the strength of soil-rock mixture and rocks. It can be seen from Figure 13b that the materials in the soil-rock slope are not uniformly distributed $\left(26.00 \sim 40.00^{\circ}\right)$. Figure $13 \mathrm{c}$ shows the development path of the plastic belt of the soil-rock slope considering the random distribution of the strength of soil-rock mixtures and rocks.

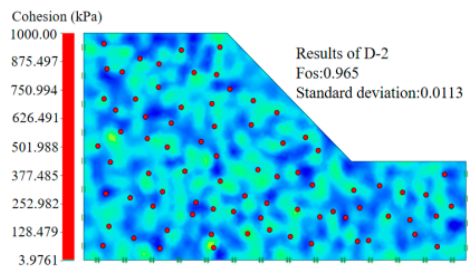

(a)

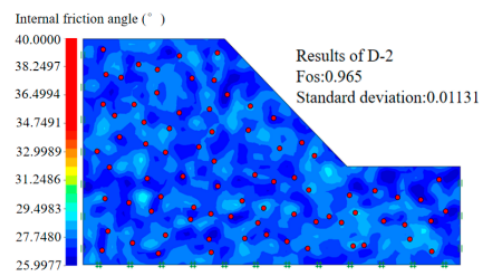

(b)

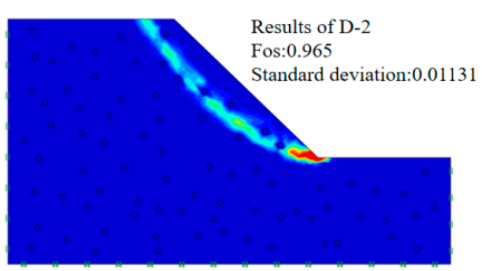

(c)

Figure 13. Results of soil-rock slope analysis of the D-2 group obtained by the Monte Carlo method: (a) cohesion distribution picture; (b) internal friction angle distribution picture; and (c) slope plastic belt picture.

Figure 14 shows the relationship between the calculated safety factor and the calculated times of the soil-rock slope of D-0, D-1, and D-2 groups. The same random distribution array is used in the D-1 group and the D-2 group, and the difference between the both groups is in distribution points of rocks. It can be found from Figure 14 that the safety factor of the soil-rock mixture slope calculated in the D-2 group is always higher than that of the D-1 group soil-rock mixture slope. The reasons are mainly related to the "obstruction" effect of the rocks on the development path of the plastic belt $[3,16]$, specifically the extension of the plastic-belt development path, change of the development direction, and adjustment of development path width.

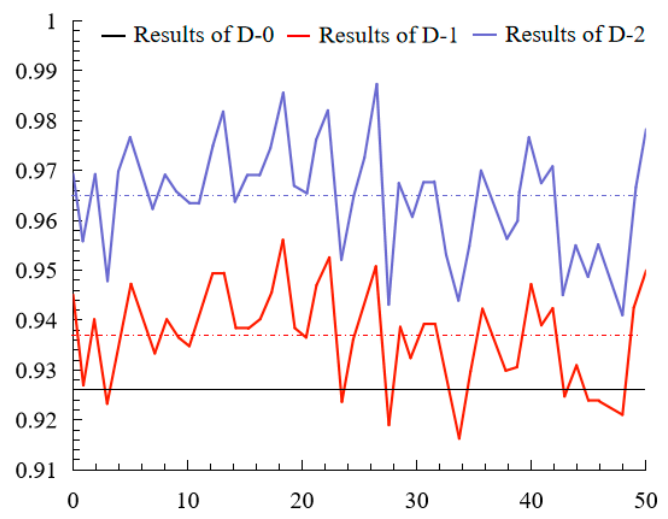

Figure 14. Stability results of soil-rock slope of D group obtained by the Monte Carlo method. 
Figure 15 shows the safety factor statistical results of the soil-rock slope in D-1 and D-2 groups. It can be found from Figure 15 that the two sets of statistical results conform to the characteristics of normal distribution basically, but the distribution frequency of the D-2 group at low Factor of safety $($ Fos $=0.943$, Frequency $=4)$ is larger than that of the D-1 group (Fos $=0.917$, Frequency $=$ 2). In addition, the standard deviation of D-2 (0.01131) is greater the D-1 (0.00959); hence, it can be concluded that slope stability analysis considering the rock strength (group D-2) will lead to greater analysis scatter error than only considering the non-uniformity of soil-rock mixtures (group D-2).

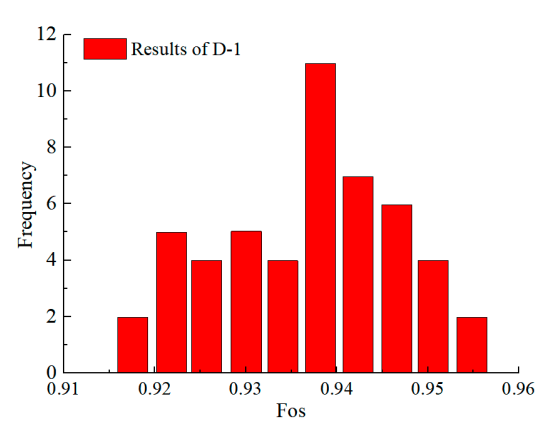

(a)

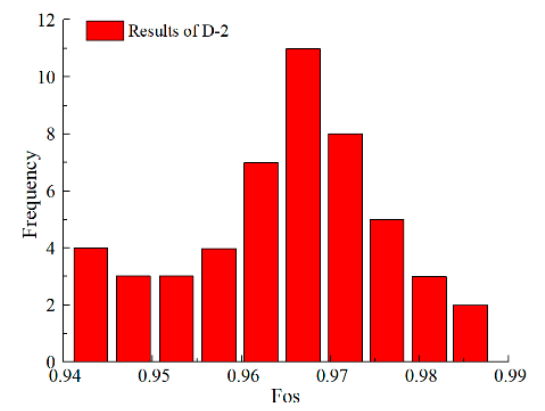

(b)

Figure 15. Statistical results of safety factors of D group obtained by the Monte Carlo method. (a) Results of group D-1; (b) results of group D-2.

Comparing the calculation results of D-0, D-1, and D-2, it can be found that the safety factor with Liu's method is always higher than 1.164, which means the slope is safe; the safety factors obtained in D-1 and D-2 by the Monte Carlo method are 0.937 and 0.965, respectively, which means the slope is dangerous. Considering that the slope has been destroyed, it is recognized that the D-1 and D-2 groups are more in line with the actual situation of the slope. Through analysis, this can be explained by the fact that Liu's method only considers the strengthening effect of rocks to slope and ignores the scatter characteristic of soil-rock mixtures and interaction between soil and rock; hence, Liu's method overestimates the stability of the soil-rock slope.

By comparing the calculation time of the three models, we can find that the calculation time of the D-0 single model is $47 \mathrm{~s}$, the calculation time of the D-1 single model is $19 \mathrm{~s}$, and the time of the single model of D-2 group is $19.3 \mathrm{~s}$. In terms of time consumption, the algorithm in this paper is more economical.

\section{Slope Stability Analysis, Considering Rock Content}

Rock content is an important parameter for stability analysis of soil-rock slopes, so the slope stability considering different rock content was studied by the Monte Carlo method. According to the different analyzing models, three groups ( $\mathrm{W}, \mathrm{T}$, and $\mathrm{R})$ were created, and the rock contents were set from $0 \%$ to $60 \%$ in each group. The specific model parameters for each analyzing model are shown in Tables 5-7. In group W, the cohesion and internal friction angle of soil-rock mixtures at different rock content were set as a specific value, which was the average value of triaxial testing results. In group $T$, the strength parameters of soil-rock mixtures were considered to be scattered, and the scatter range gradually increased with the increase of rock contents, according to testing results. In group $R$, the strength parameters of soil-rock mixtures were considered to be scattered, and some mixtures' strength was randomly changed to rock for considering the effect of rock to slope.

Table 5 shows the model parameters of group $\mathrm{W}$, which only consider the average strength parameters of soil-rock mixtures; Table 6 is the model parameters of group T, which consider the scatter strength of soil-rock mixtures; Table 7 is the model parameters of group $R$, which not only consider the scatter strength of soil-rock mixtures but also consider the strengthening effects of rocks to soil-rock mixtures. 
Table 5. Parameters of group W.

\begin{tabular}{ccccc}
\hline Number & MBP & Cohesion (kPa) & Internal Friction Angle ${ }^{\circ}$ ) & Safety Factor \\
\hline W-0 & $0 \%$ & 14.1 & 21.5 & 1.019 \\
W-1 & $10 \%$ & 11.5 & 23.3 & 0.992 \\
W-2 & $20 \%$ & 6.6 & 24 & 0.898 \\
W-3 & $30 \%$ & 4.0 & 28.7 & 0.953 \\
W-4 & $40 \%$ & 3.1 & 33 & 0.973 \\
W-5 & $50 \%$ & 2.4 & 36.4 & 1.031 \\
W-6 & $60 \%$ & & 39 & 1.063 \\
\hline
\end{tabular}

Table 6. Parameters of group T.

\begin{tabular}{cccccccc}
\hline Number & MBP & $\begin{array}{c}\text { Cohesion } \\
\mathbf{( k P a )}\end{array}$ & $\begin{array}{c}\text { Internal } \\
\text { Friction } \\
\text { Angle } \mathbf{(}^{\circ}\end{array}$ & $\begin{array}{c}\text { Standard } \\
\text { Deviation of } \\
\text { Cohesion (kPa) }\end{array}$ & $\begin{array}{c}\text { Standard } \\
\text { Deviation of } \\
\text { Internal Friction } \\
\text { Angle ( })\end{array}$ & $\begin{array}{c}\text { Average } \\
\text { Safety } \\
\text { Factor }\end{array}$ & $\begin{array}{c}\text { Standard } \\
\text { Deviation }\end{array}$ \\
\hline T-0 & $0 \%$ & 14.1 & 21.5 & 0.3 & 0.3 & 1.019 & 0.00312 \\
T-1 & $10 \%$ & 11.5 & 23.3 & 0.6 & 0.6 & 0.9914 & 0.00461 \\
T-2 & $20 \%$ & 8.6 & 24 & 0.8 & 0.9 & 0.8999 & 0.00597 \\
T-3 & $30 \%$ & 6.2 & 28.7 & 1.0 & 1.2 & 0.9479 & 0.01262 \\
T-4 & $40 \%$ & 4.0 & 33 & 1.2 & 1.5 & 0.9678 & 0.02470 \\
T-5 & $50 \%$ & 3.1 & 36.4 & 1.4 & 1.8 & 1.02 & 0.03866 \\
T-6 & $60 \%$ & 2.4 & 39 & 1.6 & 2.1 & 1.053 & 0.04056 \\
\hline
\end{tabular}

Table 7. Parameters of group R.

\begin{tabular}{|c|c|c|c|c|c|c|c|c|}
\hline Number & МBP & $\begin{array}{c}\text { Cohesion } \\
(\mathbf{k P a})\end{array}$ & $\begin{array}{l}\text { Internal } \\
\text { Friction } \\
\text { Angle }\left({ }^{\circ}\right)\end{array}$ & $\begin{array}{c}\text { Standard } \\
\text { Deviation of } \\
\text { Cohesion (kPa) }\end{array}$ & $\begin{array}{c}\text { Standard Deviation } \\
\text { of Internal Friction } \\
\text { Angle }\left({ }^{\circ}\right)\end{array}$ & $\begin{array}{c}\text { Probability } \\
\text { of Rock }\end{array}$ & $\begin{array}{l}\text { Average } \\
\text { Safety } \\
\text { Factor }\end{array}$ & $\begin{array}{l}\text { Standard } \\
\text { Deviation }\end{array}$ \\
\hline R-0 & $0 \%$ & 14.1 & 21.5 & 0.3 & 0.3 & $0 \%$ & 1.019 & 0.00312 \\
\hline R-1 & $10 \%$ & 11.5 & 23.3 & 0.6 & 0.6 & $10 \%$ & 0.9968 & 0.00391 \\
\hline $\mathrm{R}-2$ & $20 \%$ & 8.6 & 24 & 0.8 & 0.9 & $20 \%$ & 0.9022 & 0.00666 \\
\hline $\mathrm{R}-3$ & $30 \%$ & 6.2 & 28.7 & 1.0 & 1.2 & $30 \%$ & 0.9623 & 0.00934 \\
\hline R-6 & $60 \%$ & 2.4 & 39 & 1.6 & 2.1 & $60 \%$ & 1.076 & 0.04573 \\
\hline
\end{tabular}

Details: The cohesion of rock is $1000 \mathrm{kPa}$, and internal friction angle of rock is $40^{\circ}$.

Figure 16 shows the relationship between the safety factor of the soil-rock mixture in groups $\mathrm{W}, \mathrm{T}$, and $\mathrm{R}$ and rock content, and it can be found that, with the increase of rock content, the safety factors of slopes increases when rock content is in $0 \% \sim 20 \%$, and then decreases when the rock content is larger than $20 \%$, in which the minimum safety factor was obtained at $20 \%$ rock content.

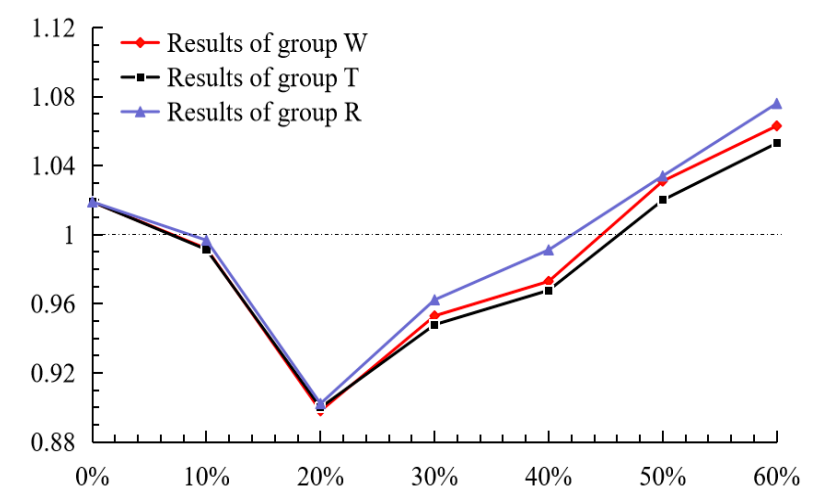

Figure 16. Variations of safety factor of groups $\mathrm{W}, \mathrm{T}$, and $\mathrm{R}$ to rock contents.

Comparing the calculation results of the $\mathrm{W}, \mathrm{T}$, and $\mathrm{R}$ groups, it can be found that, when the rock content is less than $20 \%$, the calculation results of the three calculation methods are similar. When the 
rock content is more than $20 \%$, the calculation result of the $\mathrm{R}$ group is higher than that of the $\mathrm{W}$ and $\mathrm{T}$ groups; when the rock content is greater than $30 \%$, the calculation result of the $\mathrm{W}$ group is larger than the calculation result of the T group. The explanation for these results is that, when the rock content is more than $30 \%$, the scatter strength of soil-rock mixtures leads to the reduced characteristic of safety factor of the soil-rock slope. In other words, the slope is prone to landslides; hence, the safety factor of group $\mathrm{T}$ is smaller than that of group $\mathrm{W}$. When considering the strengthening characteristic of rocks and slope stability, rock distributions will affect the development path of plastic belt in the slope, which is active to improve the stability of slope, so the safety factor of group $\mathrm{R}$ is greater than that of group W.

It can be seen from Figure 17 that, when the rock content is less than $30 \%$, the standard deviation of the safety factor of the slope increases slowly; when the amount of stone is more than $30 \%$, the standard deviation of the safety factor of the slope increases rapidly. Therefore, when analyzing the stability of soil-rock slopes with the rock content higher than $30 \%$, the reliability of the applied analysis parameters should be noted.

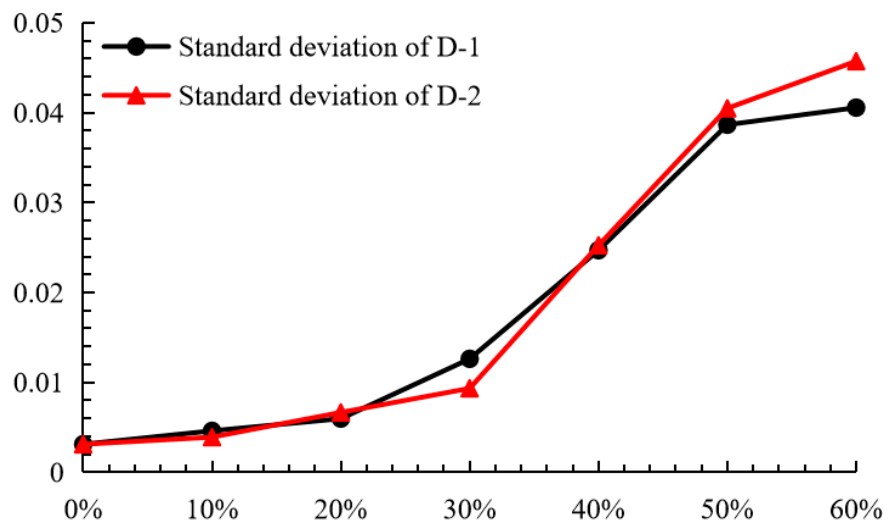

Figure 17. Variations of Standard deviation of groups $\mathrm{T}$ and $\mathrm{R}$ to rock contents.

\section{Discussion About Stability Estimation of the Soil-Rock Slope}

\subsection{Discussion About Characteristic Parameters of the Soil-Rock Slope}

In the geological survey process, many methods can be used to obtain the characteristic parameters of the soil-rock mixture slope. The three typical methods (shown in Figure 18) are drill sampling, photography for landslides, and scanning by X-ray.

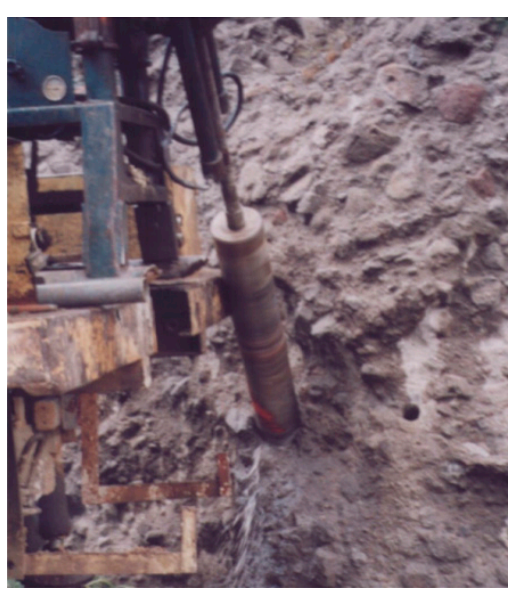

(a)

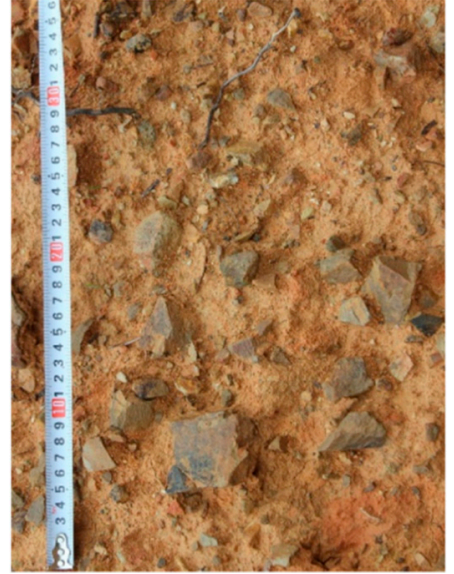

(b)

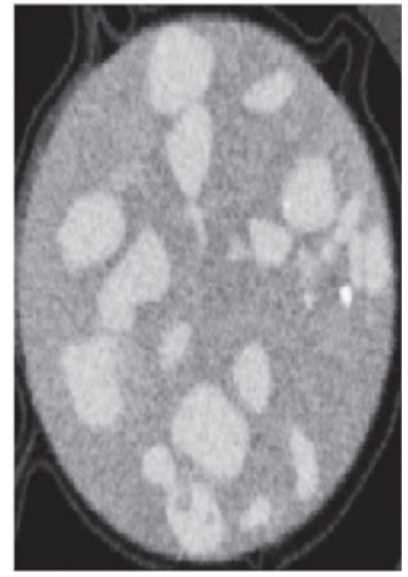

(c)

Figure 18. Feature recognition methods of soil-rock slope: (a) In situ sampling [8]; (b) photography for soil-rock mixtures [18]; and (c) scanning by X-ray [4]. 
Drill sampling [8] is a commonly used geological survey method. The soil can be directly taken out by drilling. This method not only obtains the most original parameters of materials but also determines the mixing content, distribution, and shape characteristics of rocks in the soil-rock slope, according to the characteristics of soil and rocks in the drilling-hole samples.

Photography for landslides [12,13] (shown in Figure 18b) is based on the failure surface pictures of soil-rock slopes, to obtain some characteristic parameters of soil-rock slopes, such as rock shapes, sizes, and distribution characteristics, and so on. Then, according to the obtained characteristic parameters, the stability of soil-rock slopes can be analyzed.

Scanning by $\mathrm{X}$-ray $[4,43]$ can identify the internal characteristics of the rocks inside the slope without damage. On the basis of scanning images, the rocks' and cracks' locations in soil-rock mixtures are obtained directly, which is meaningful for evaluating the mechanical properties of soil-rock mixtures and establishing soil-rock slope models. Huge investment in the early stage leads to less appliance of the stability analysis of the soil-rock slope, and this method is generally used in model tests or estimations of soil-rock mixtures.

\subsection{Discussion on the Applicability of Analytical Methods}

There are many methods for analyzing the stability of soil-rock slopes, which are mainly divided into four categories: (1) homogenized soil slope model that the material strength in slope is mainly controlled by soil; (2) homogenized soil-rock slope model that the material strength in slope is related to soil-rock mixtures; (3) a slope model considering the strengthening effect of the rocks; (4) and a slope model considering the dispersion of the strength of the soil-rock mixture. The details for analyzing the soil-rock slopes by these models are as follows.

Homogenized soil slope models [8,44]: The stability of the soil-rock slope is recognized by a combination of results of uniform soil slope and the corresponding reducing or increasing coefficient. In this method, the reducing or increasing coefficient is based on engineering experience, leading to lower reliability of analyzing results.

Homogenized soil-rock slope model considering soil-rock mixture strength $[8,18]$ : This method considers the soil-rock mixture as homogeneous material. According to the obtained soil-rock mixture strength parameter as the main parameter of slope stability analysis, the method has poor applicability to slopes containing large rocks, and the dispersion of the strength of the soil-rock mixture material cannot be considered.

A slope model considering the strengthening effect of the rocks $[3,13]$ : This method establishes the corresponding rock feature unit in the analysis model and fully considers the effect of the rock content on the slope stability improvement, but the method ignores the weak soil-rock interface and often overestimates the stability of the soil-rock slope.

A slope model considering the dispersion of the strength of the soil-rock mixture: This method is based on a Monte Carlo algorithm, which can simultaneously consider the influence of soil-rock mixture strength scatter, weak soil-rock interface (by adding low strength material), and rock strengthening features on slope stability (by adding high strength material) and obtain the stability of the soil-rock mixture slope by statistical method. The calculation results are more reliable.

Combined with the analysis results of the stability of the soil-rock mixture slope in Section 4, this study aimed to calculate the soil-rock slopes with different sizes and puts forward some suggestions for the stability analysis of soil-rock slopes.

(1) In the process of sampling for stability analysis of soil-rock slopes, it is advised to survey in the main affecting area first, and then survey in the secondary affecting area. The definition of affecting area is shown in Figure 19, that $\mathrm{L}$ is the basic length $[3,16]$. In this process, $\mathrm{L}$ is the horizontal length of plastic belt to slope top in homogeneous soil slope models, and L is $4 \mathrm{~m}$ in the article.

(2) When the rock size is $0.1 \sim 0.4 \mathrm{Ls}$ (Ls is the width of slope) in the main affecting area, it is advised to use analysis models with the Monte Carlo method, considering the strengthening effect of 
rocks. When the soil-rock slope is more easily affected by rainfall, traffic load, and other factors, it is advised to use analysis models with the Monte Carlo method, considering the scatter strength of soil-rock mixtures. When the soil-rock interface is weak, it is advised to use analysis models with the Monte Carlo method, considering the weakening effects of soil-rock interface area.

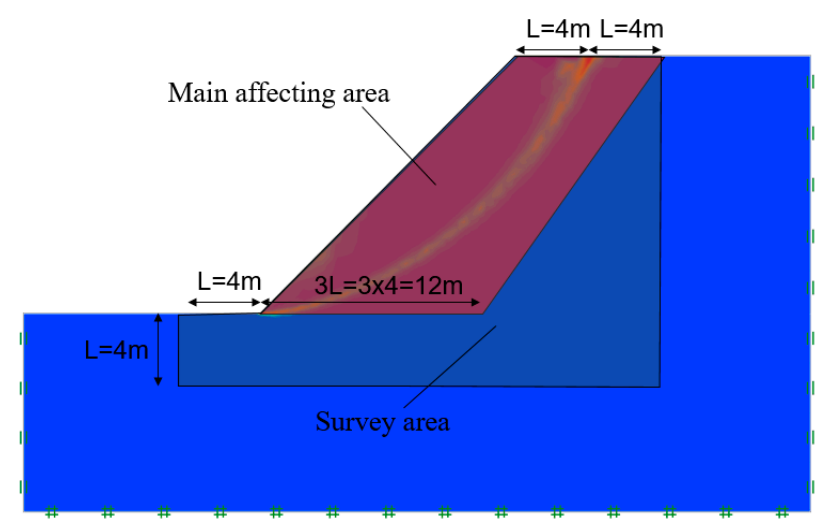

Figure 19. Area division diagram of soil-and-rock-slope area.

\section{Conclusions}

Based on the Monte Carlo method, a stability analysis method for soil-rock slopes considering the scatter strength characteristics of soil-rock mixture was presented in this paper. Through the comparison with Liu's algorithm, the superiority of the algorithm in the slope stability analysis of soil-rock mixture was illustrated. The influence of the rock content on the stability of soil-rock slopes was studied by the algorithm, and the application process of the algorithm to the stability analysis of soil-rock slopes is put forward.

(1) The Monte Carlo method and its application in stability analysis of soil-rock slopes are introduced in detail.

(2) Based on the strength of soil-rock mixtures arising from the in situ samples and remade samples, the scatter characteristic of cohesion and internal friction angle for soil-rock mixtures were proved, and it can be concluded that the cohesion reduces with the increase of rock content, and the internal friction angle increases with the increase of rock content.

(3) Through comparing with the failed slope and Liu's method for analyzing the stability of soil-rock slopes, it was proved that analyzing the soil-rock slope with the Monte Carlo method is reasonable and economical.

(4) The stability of the soil-rock slope, considering strengthening effect of rocks to slope and different rock contents, was studied, and the results show that with the increase of rock content, the stability of the soil-rock slope reduces first and then increases, and the minimum value was achieved at $20 \%$ rock content. When the rock content is over $30 \%$, the soil-rock slope achieves the largest safety factor, when considering the strengthening effect of rocks, and achieves the smallest safety factor when considering the scatter strength of soil-rock mixtures.

(5) Based on a large number of examples and existing documents, the investigation area for the optimum parameter characteristics of soil-rock mixture in slope stability analysis is proposed. Taking these into account, the chosen models were put forward for different situations, to study which situations are suitable for analysis models, considering the weak soil-rock interface area and the strengthening effect of rocks.

It should be noted that, in this paper, a Monte Carlo approach was used to estimate the stability of soil-rock slopes, only considering the non-uniformity of materials. In order to better serve the project about soil-rock slope reinforcement, the stability of soil-rock slope considering anchors, netting, piles, 
or geo-grids should be studied. In the forthcoming study, it is a good way to check the accuracy of Monte Carlo method by comparing its results of soil-rock slope with other methods, such as artificial neural networks.

Author Contributions: The authors confirm contribution to the paper as follows: writing-original draft, X.H. and A.Z.; writing-review and editing, W.W. and N.L.; validation, P.J. All authors have read and agreed to the published version of the manuscript.

Funding: This research was funded by the National Natural Science Foundation of China (Grant numbers $[51579119,41772311])$, the Natural Science Fund for Colleges Universities of Jiangsu Province (Grant number [17KJB560003]), the Zhejiang Provincial Natural Science Foundation of China (Grant number [LY17E080016]), and the Research Fund of Zhejiang Provincial Department of Housing and Urban-Rural Development (2017K179, 2016K130).

Conflicts of Interest: The authors declare no conflict of interest.

\section{References}

1. Xu, W.J.; Xu, Q.; Hu, R.L. Study on the shear strength of soil-rock mixture by large scale direct shear test. Int. J. Rock Mech. Min. Sci. 2011, 48, 1235-1247.

2. Coli, N.; Berry, P.; Boldini, D. In situ non-conventional shear tests for the mechanical characterisation of a bimrock. Int. J. Rock Mech. Min. Sci. 2011, 48, 95-102. [CrossRef]

3. Liu, S.Q.; Huang, X.W.; Zhou, A.Z.; Hu, J.; Wang, W. Soil-Rock Slope Stability Analysis by Considering the Nonuniformity of Rock. Math. Probl. Eng. 2018, 2018, 1-15. [CrossRef]

4. Wang, Y.; Li, C.H.; Hu, Y.Z. Use of X-ray computed tomography to investigate the effect of rock blocks on meso-structural changes in soil-rock mixture under triaxial deformation. Constr. Build. Mater. 2018, 164, 386-399. [CrossRef]

5. Zhang, H.; Xu, W.; Yu, Y. Triaxial tests of soil-rock mixtures with different rock block distributions. Soils Found. 2016, 56, 44-56. [CrossRef]

6. Zhang, Y. Study on strength, deformation characteristics and interaction between soil and stone of soil-rock mixture. CET J. 2017, 59, 985-990.

7. Wang, W.; Zhang, C.; Li, N.; Tao, F.F.; Yao, K. Characterisation of nano magnesia-cement-reinforced seashore soft soil by direct-shear test. Mar. Georesour. Geotec. 2019, 37, 989-998. [CrossRef]

8. Kalender, A.; Sonmez, H.; Medley, E.; Tunusluoglu, C.; Kasapoglu, K.E. An approach to predicting the overall strengths of unwelded bimrocks and bimsoils. Eng. Geol. 2014, 183, 65-79. [CrossRef]

9. Huang, D.; Gu, D.M. Influence of filling-drawdown cycles of the Three Gorges reservoir on deformation and failure behaviors of anaclinal rock slopes in the Wu Gorge. Geomorphology 2017, 295, 489-506. [CrossRef]

10. Li, R.W.; Wang, N.Q. Landside susceptibility mapping for the muchuan county (China): A comparison between bivariate statistical models (WOE, EBF, and IOE) and their ensembles with logistic regression. Symmetry 2019, 11, 762. [CrossRef]

11. Xu, W.J.; Hu, L.M.; Gao, W. Random generation of the meso-structure of a soil-rock mixture and its application in the study of the mechanical behavior in a landslide dam. Int. J. Rock Mechmin. 2016, 86, 166-178. [CrossRef]

12. Gao, W.; Gao, W.; Hu, R.L.; Xu, P.; Xia, J. Microtremor survey and stability analysis of a soil-rock mixture landslide: A case study in Baidian town, China. Landslides 2018, 15, 1951-1961. [CrossRef]

13. Yang, Y.; Sun, G.; Zheng, H.; Qi, Y. Investigation of the sequential excavation of a soil-rock-mixture slope using the numerical manifold method. Eng. Geol. 2019, 256, 93-109. [CrossRef]

14. Khorasani, E.; Amini, M.; Hossaini, M.F.; Medley, E. Statistical analysis of bimslope stability using physical and numerical models. Eng. Geol. 2019. [CrossRef]

15. Wang, T.; Zhang, G. Failure behavior of soil-rock mixture slopes based on centrifuge model test. J. Mt. Sci. Engl. 2019, 16, 1928-1942. [CrossRef]

16. Napoli, M.L.; Barbero, M.; Ravera, E.; Scavia, C. A stochastic approach to slope stability analysis in bimrocks. Int. J. Rock Mech. Min. Sci. 2018, 10, 41-49. [CrossRef]

17. Liu, Y.; Xiao, H.; Yao, K.; Hu, J.; Wei, H. Rock-soil slope stability analysis by two-phase random media and finite elements. Geosci. Front. 2018, 9, 1649-1655. [CrossRef]

18. Meng, Q.X.; Wang, H.L.; Xu, W.Y.; Xu, J.; Cai, M.; Zhang, Q. Multiscale strength reduction method for heterogeneous slope using hierarchical FEM/DEM modeling. Comput. Geotech. 2019, 115, 103164. [CrossRef] 
19. Xu, H.F.; Liu, L.L.; Liu, Y. Water-induced changes in mechanical parameters of soil-rock mixture and their effect on talus slope stability. Geomech. Eng. 2019, 4, 353-362.

20. Afifipour, M.; Moarefvand, P. Mechanical behavior of bimrocks having high rock block proportion. Int. J. Rock Mech. Min. Sci. 2014, 65, 40-48. [CrossRef]

21. Huang, X.W.; Liu, S.Q.; Sui, X.L.; Hu, Y. Earthquake response analysis of soil-rock slope based on distribution of rocks. In Proceedings of the 2018 International Forum on Construction, Aviation and Environmental Engineering-Internet of Things, Guangzhou, China, 2 July 2018; p. 175.

22. Hanif, M.H.; Adnan, M.; Shah, S.A.R.; Khan, N.M.; Nadeem, M.; Javed, J.; Akbar, M.W.; Farooq, A.; Waseem, M. Rainfall runoff analysis and systainable soil bed optumization engineering process: Application of an advanced decision-making technique. Symmetry 2019, 11, 1224. [CrossRef]

23. Xiong, X.; Shi, Z.; Xiong, Y.; Peng, M.; Ma, X.; Zhang, F. Unsaturated slope stability around the Three Gorges Reservoir under various combinations of rainfall and water level fluctuation. Eng. Geol. 2019, 1, 105231. [CrossRef]

24. Hoggan, P.E.; Brändas, E.J.; Maruani, J.; Piecuch, P.; Delgado-Barrio, G. Preface: Advances in the Theory of Quantum Systems in Chemistry and Physics; Springer: Berlin/Heidelberg, Germany, 2012.

25. Cheng, Y.W.; Zhu, H.P.; Hu, K.; Wu, J.; Shao, X.Y. Reliability prediction of machinery with multiple degradation characteristics using double-Wiener process and Monte Carlo algorithm. Mech. Syst. Signal Pr. 2019, 134, 106333. [CrossRef]

26. Liu, X.; Li, D.Q.; Cao, Z.J.; Wang, Y. Adaptive Monte Carlo simulation method for system reliability analysis of slope stability based on limit equilibrium methods. Eng. Geol. 2020, 264, 105384. [CrossRef]

27. Pasculli, A.; Calista, M.; Sciarra, N. Variability of local stress states resulting from the application of Monte Carlo and finite difference methods to the stability study of a selected slope. Eng. Geol. 2018, 245, 370-389. [CrossRef]

28. Dyson, A.P.; Tolooiyan, A. Prediction and classification for finite element slope stability analysis by random field comparison. Comput. Geotech. 2019, 109, 117-129. [CrossRef]

29. Yao, K.; Chen, Q.; Xiao, H.; Liu, Y.; Lee, F.H. Small-strain shear modulus of cement-treated marine clay. J. Mater. Civil. Eng. 2020, 32, 04020114. [CrossRef]

30. Yao, K.; An, D.L.; Wang, W.; Li, N.; Zhang, Z.; Zhou, A.Z. Effect of nano-mgo on mechanical performance of cement stabilized silty clay. Mar. Georesour. Geotec. 2020, 38, 250-255. [CrossRef]

31. Wang, W.; Li, Y.; Yao, K.; Li, N.; Zhou, A.Z.; Zhang, Z. Strength properties of nano-MgO and cement stabilized coastal silty clay subjected to sulfuric acid attack. Mar. Georesour. Geotec. 2019. [CrossRef]

32. Wang, W.; Fu, Y.; Zhang, Z.; Li, N.; Zhou, A.Z. Mathematical models for stress-strain behavior of nano magnesia-cement-reinforced seashore soft soil. Mathematics 2020, 8, 456. [CrossRef]

33. Raphael, B.; Smith, I.F.C. A direct stochastic algorithm for global search. Appl. Math. Comput. 2003, 146, 729-758. [CrossRef]

34. Thistleton, W.J.; Marsh, J.A.; Nelson, K. Generalized Box-Muller Method for Generating q-Gaussian Random Deviates. IEEE Trans. Inform. Theory 2007, 53, 4805-4810. [CrossRef]

35. Rodrigues, D.J. A simple generalization of the Box-Muller method for obtaining a pair of correlated standard normal variables. J. Stat. Comput. Sim. 2010, 80, 953-958.

36. Jakob, S.; Fabian, R.; Martin, S.; Jens, L. Significance of preferential flow at the rock soil interface in a semi-arid karst environment. Catena 2014, 123, 1-10.

37. Ákos, T.; Gong, Q.M.; Zhao, J. Case studies of TBM tunneling performance in rock-soil interface mixed ground. Tunn. Undergr. Space Technol. 2013, 38, 140-150.

38. Chang, W.; Phantachang, T. Effects of gravel content on shear resistance of gravelly soils. Eng. Geol. 2016, 207, 78-90. [CrossRef]

39. Chinese National Geotechnical Test Standard, GB/T 50123-1999. China Planning Press, 1999. Available online: http://www.zys168.net/Upload/DownLoad/DownLoadFile/20107191920846.pdf (accessed on 26 October 2019). (In Chinese).

40. Meng, Q.X.; Wang, H.L.; Xu, W.Y.; Cai, M. A numerical homogenization study of the elastic property of a soil-rock mixture using random mesostructure generation. Comput. Geotech. 2018, 98, 48-57. [CrossRef]

41. Zhang, W.J.; Qing, L.; Li, H.L. Research on shear behavior characteristics of soil-rock mixture. Int. J. Earth Sci. $2015,6,2620-2625$. 
42. Gong, J.; Liu, J. Analysis on the Mechanical Behaviors of Soil-rock Mixtures Using Scatter Element Method. Procedia Eng. 2015, 102, 1783-1792. [CrossRef]

43. Huang, X.W.; Zhou, A.Z.; Wang, W.; Jiang, P.M. Characterization of the dynamic properties of clay-gravel mixtures at low strain level. Sustainability 2020, 12, 1616. [CrossRef]

44. Qian, Z.G.; Li, A.J.; Chen, W.C.; Lyamin, A.V.; Jiang, J.C. An artificial neural network approach to inhomogeneous soil slope stability predictions based on limit analysis methods. Soils Found. 2019, 59, 556-569. [CrossRef]

(C) 2020 by the authors. Licensee MDPI, Basel, Switzerland. This article is an open access article distributed under the terms and conditions of the Creative Commons Attribution (CC BY) license (http://creativecommons.org/licenses/by/4.0/). 